\title{
Polymerization with Presence of Polymers
}

\section{Solution Polymerization of Vinyl Acetate with Presence of Polyvinyl Alcohol}

\section{By Takuhiko Motoyama ${ }^{\dagger}$ and Seizo Okamura}

Soluble grafted polymer is obtained by the solution polymerization of vinyl acetate in $50 \%$ acetic acid aqueous solution with presence of polyvinyl alcohol. Grafting efficiency of polyvinyl alcohol becomes larger as the degree of polymerization increases, and these mechanism are considered.

第 4 報 アクリロニトリル-酢酸ビニルグラフト

重合物の製造ならびに紡系

(1957 年 9 月 9 日受理)

山下隆 男* ・岡村誠三

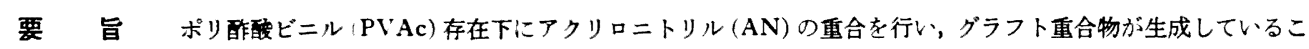

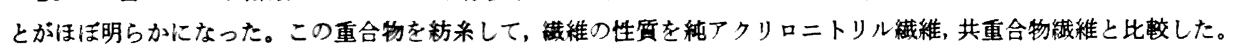

1. 緒 言

高分子の存在における各種モノマーの重合により,グラフト重合物をつくることは種々の組合せについて 広く研究されている”。本報告においてはわれわれの研究室で古くから脷上げてきている AN-VAc の組 合せについてグラフト重合を行い，生成物について検討した。また従来 AN-VAc 共重合物の紡系に関する 研究も行ってきたが21，VAc 含量の増加とともに䋊維の耐熱性は低下した。この点グラフト重合物を原料と すれば耐熱性を低下しない可能性もある。このような観点から以下の実験を行った。

\section{2. 重合}

乳化重合と溶液重合とを行った。

乳化重合は,まず1種のモノマーを乳化剂としてドデシル硫酸ソータ，触媒として過硫酸カリを用いて乳 化重合してストックポリマーをつくり，このェマルジョンに他のモノマーを添加し過硫酸カリを追加して重 合を行った。

溶液重合はベンゼンを溶剤とし，過酸化ベンゾイルを触媒として，PVAc 存在下でANの重合を行った。 重合が始まると液が白濁した。

このよらにして得られたポリマーをつセトンで抽出し, 不溶部分と可溶部分とに分離して, 各々のポリマ 一をキェルダール法で窒素定量し,アクリロニトリル含有量を求めた。乳化重合についての結果を第 1 表に, 溶液重合についての結果を第 2 表に示す。

$\dagger$ The Institute for Chemical Research Kyoto, University (Kosobe, Takatsuki-shi, near Osaka)

* 京都大学工学部䋺維化学教室 (京都市左京区吉田) 
第 1 㤗 乳 化 重 合 $\left(60^{\circ} \mathrm{C}, 4\right.$ 時間)

\begin{tabular}{|c|c|c|c|c|c|c|c|c|c|c|c|}
\hline \multirow{2}{*}{$\begin{array}{l}\text { 実験 } \\
\text { 番号 }\end{array}$} & \multicolumn{4}{|c|}{ 重 合 条 件 } & \multicolumn{2}{|c|}{ ポリマー } & \multicolumn{2}{|c|}{$\begin{array}{c}\text { アトン不溶 } \\
\text { 部分 }\end{array}$} & \multicolumn{2}{|c|}{$\begin{array}{c}\text { アセトン可溶 } \\
\text { 部分 }\end{array}$} & \multirow[b]{2}{*}{$f_{P}$} \\
\hline & $\begin{array}{c}\text { ストック } \\
\text { ポリマー } \\
(\mathrm{g})\end{array}$ & $\begin{array}{c}\text { 添加モ } \\
\begin{array}{c}\text { マ } \\
(\mathrm{g})\end{array}\end{array}$ & $\begin{array}{c}\mathrm{K}_{2} \mathrm{~S}_{2} \mathrm{O}_{8} \\
(\mathrm{~g})\end{array}$ & $\begin{array}{r}\mathrm{H}_{2} \mathrm{O} \\
(\mathrm{g})\end{array}$ & \begin{tabular}{|}
$\mid$ 添加モJ \\
マーの重 \\
合率 $(\%)$ \\
\end{tabular} & {$\left[\begin{array}{c}\text { 生成ポリ } \\
\text {-中Nの } \\
\text { AN (wt \%) }\end{array}\right.$} & $\begin{array}{c}\text { 重 量 } \\
(\mathrm{g}) \\
\end{array}$ & $\begin{array}{c}\mathrm{AN} \\
(w \mathrm{t} \%)\end{array}$ & $\begin{array}{c}\text { 重 量 } \\
(\mathrm{g})\end{array}$ & $\begin{array}{c}\text { AN } \\
(w t \%)\end{array}$ & \\
\hline 1 & $\begin{array}{l}\text { PVAc } \\
5.15\end{array}$ & $\begin{array}{l}\mathrm{AN}_{20.2} \\
\end{array}$ & 0.100 & 80 & 96.3 & 77.97 & $0.4926 *$ & 89.19 & $0.0399 *$ & 53.71 & - \\
\hline 2 & ${ }_{4.16}$ & $\begin{array}{l}\text { VAc } \\
1.56\end{array}$ & 0.080 & 8.0 & 81.9 & 74.07 & 0.4792 & 88.85 & 0.0781 & 1.87 & 0.52 \\
\hline 3 & $\begin{array}{r}\mathrm{PAN}_{4.16} \\
\end{array}$ & $\begin{array}{l}\text { VAc } \\
7.80\end{array}$ & 0.080 & 25.0 & 96.0 & 35.18 & 0.3977 & 61.35 & 0.2685 & 0.54 & 0.45 \\
\hline
\end{tabular}

* 1 度ジメチルホルムアマイドに溶解後アセトンで沈殿

第 2 衰 溶 液 重 $\left(60^{\circ} \mathrm{C}\right)$

\begin{tabular}{|c|c|c|c|c|c|c|c|c|c|c|c|c|c|}
\hline \multirow{2}{*}{$\begin{array}{l}\text { 実験 } \\
\text { 番号 }\end{array}$} & \multicolumn{2}{|c|}{$\begin{array}{c}\text { ストック } \\
\text { PVAc }\end{array}$} & \multirow{2}{*}{ 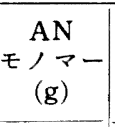 } & \multirow{2}{*}{$\begin{array}{l}\text { ベン } \\
\text { ゼン } \\
\text { (cc) }\end{array}$} & \multirow{2}{*}{$\begin{array}{c}\text { BPO } \\
(\mathrm{g})\end{array}$} & \multirow{2}{*}{$\begin{array}{l}\text { 重盒 } \\
\text { (hr) }\end{array}$} & \multirow{2}{*}{$\begin{array}{c}\text { 生成 } \\
\text { (g) }\end{array}$} & \multirow{2}{*}{$\begin{array}{c}\mathrm{AN} \\
\text { 重合率 } \\
(\%) \\
\end{array}$} & \multicolumn{2}{|c|}{$\begin{array}{l}\text { ア七トン } \\
\text { 不溶部分 }\end{array}$} & \multicolumn{2}{|c|}{$\begin{array}{l}\text { アセトン } \\
\text { 可溶部分 }\end{array}$} & \multirow{2}{*}{$f_{P}$} \\
\hline & $\begin{array}{c}\text { 重 量 } \\
(\mathrm{g})\end{array}$ & $\begin{array}{l}\text { 平 均 } \\
\text { 重合度 }\end{array}$ & & & & & & & $\begin{array}{c}\text { 重 量 } \\
(\mathrm{g})\end{array}$ & $\begin{array}{c}\mathrm{AN} \\
(\text { wt } \%)\end{array}$ & $\begin{array}{c}\text { 重 量 } \\
(\mathrm{g})\end{array}$ & $\begin{array}{c}\mathrm{AN} \\
(\mathrm{wt} \%)\end{array}$ & \\
\hline 4 & 2.0 & 264 & 6.425 & 20 & 0.064 & 4.0 & 4.7096 & 57.7 & 3.880 & 95.55 & 1.83 & 0 & 0.09 \\
\hline 5 & 2.0 & 264 & 12.85 & 20 & 0.129 & 4.0 & 12.730 & 83.7 & 11.06 & 93.03 & 1.67 & 0 & 0.17 \\
\hline 6 & 2.0 & 264 & 25.70 & 20 & 0.257 & 4.0 & 25.89 & 93.1 & 24.38 & 95.79 & 1.51 & 0 & 0.25 \\
\hline 7 & 1.5 & 5640 & 15.0 & 16.5 & 0.075 & 3.0 & 12.99 & 69.6 & 12.00 & 93.69 & 0.987 & - & 0.34 \\
\hline \multirow[t]{2}{*}{8} & 7.5 & 5640 & 7.5 & 15.0 & 0.038 & 6.0 & 12.38 & 65.0 & 5.074 & 70.21 & 7.305 & - & 0.27 \\
\hline & 3.0 & 5290 & 13.7 & 25 & 0.064 & 1.0 & 4.881 & 13.7 & 2.163 & 94.58 & 2.718 & 1.00 & 0.09 \\
\hline 10 & 3.0 & 5290 & 13.7 & 25 & 0.064 & 2.0 & 7.532 & 33.0 & 4.855 & - & 2.677 & 0.54 & 0.11 \\
\hline 11 & 3.0 & 5290 & 13.7 & 25 & 0.064 & 5.5 & 13.21 & 74.6 & 10.706 & 94.18 & 2.510 & 0.57 & 0.16 \\
\hline 12 & - & - & 13.7 & 25 & 0.064 & 2.0 & 4.705 & 34.3 & 4.700 & 98.29 & - & - & - \\
\hline 13 & - & - & 15.0 & 15 & 0.075 & 4.0 & 12.13 & 80.8 & 12.05 & 97.77 & - & - & - \\
\hline
\end{tabular}

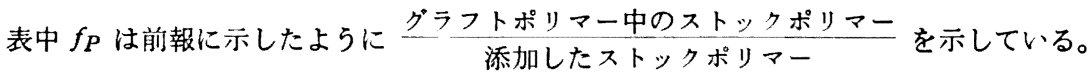

重合体中のア七トン可溶部分は実験番号 1 のものを除きほほとん ど窒素を含有せず, 純 PVAc と考えられる。一方アセトン不溶部 分は純 PAN ではなくPVAc を含有していることがわかった。

第 2 表中の $\mathrm{PVAc} / \mathrm{AN}$ を $f_{P}$ に対してプロットすると第 1 図の ようであって，この比が小さい方が $f_{P}$ が大きくなっている。

\section{3. 重合体の分别}

上述の結果より重合体中のアセトン不溶部分は純 PAN と ANVAc グラフト共重合物との混合物であると考えられるので，この 重合物をジメチルホルムアマイドに溶解し，アセトンを添加して分

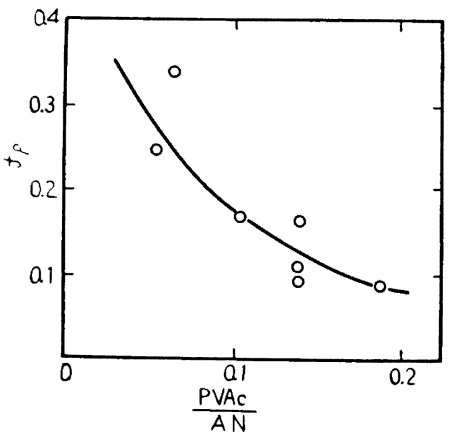

第 1 図 PVAc/AN と $f_{P}$ との関係 別沈殿を行った。1 例を第 3 表に示す。同時に比較のため, PAN とPVAc との等量混合物も分別した。 
第3 表 重合物の分別

$\left(0.2 \%\right.$ ジメチルホルムアミド溶液 $60 \mathrm{cc} に 20^{\circ} \mathrm{C}$ でアセトンを注加, 1 夜放置後沈殿を分離し, さらにア セトンを注加, これをくり返す)

\begin{tabular}{|c|c|c|c|c|c|c|c|c|c|}
\hline & アセトン添加全量 (cc) & 50 & 55 & 60 & 65 & 70 & 75 & 80 & $\begin{array}{l}\text { 濃縮し } \\
\text { 水で沈殿 }\end{array}$ \\
\hline $\begin{array}{c}\text { PVAc }(\bar{P}=1040) \text { と PAN } \\
(\bar{P}=1810) \text { との等量混合物 } \\
(\text { AN } 50.0 \text { wt \%) }\end{array}$ & $\begin{array}{l}\text { 収量 (\%) } \\
\text { 内 AN (wt \%) }\end{array}$ & $\begin{array}{l}12.9 \\
95.0\end{array}$ & $\begin{array}{l}23.0 \\
93.3\end{array}$ & $\begin{array}{l}13.8 \\
94.0\end{array}$ & trace & なし & なし & なし & $\begin{array}{r}48.7 \\
4.0\end{array}$ \\
\hline $\begin{array}{c}\text { PVAc 存在下に AN を重 } \\
\text { 合して得たポリマー } \\
\text { (AN } 51.3 \text { wt \%ó) }\end{array}$ & $\begin{array}{l}\text { 収量 }\left(\sigma_{0}^{\circ}\right) \\
\text { 内 } \mathrm{AN}(\mathrm{wt} \%)\end{array}$ & なし & なし & $\begin{array}{r}7.4 \\
90.5\end{array}$ & $\begin{array}{l}37.0 \\
51.5\end{array}$ & $\begin{array}{l}32.4 \\
46.8\end{array}$ & $\begin{array}{l}19.6 \\
47.3\end{array}$ & なし & trace \\
\hline
\end{tabular}

以上の実験で低重合度のPAN がアセトン可溶であるためなどの原因で分離は完全ではないが，上の $2 つ$ のポリマーの沈殿性は全く相違し，PVAc 存在下で AN を重合するとグラフト重合物が生成しているものと 考えられる。なお PVAc とPAN との浱厚溶液は放圆により脱混合するが，PVAc 存在下に AN を重合さ せたポリマーの濃厚溶液は脱混合しないこともグラフト重合物生成を支持する。グラフトポリマー生成の確 実な証明は後に行う予定であるが，上述の結果からもほぼ明らかである。

\section{4.赤系ならびに㳦維の性罂}

以上のようにしてつくった AN-VAc グラフト共重合物をジメチルホルムアマイド溶液から水, 水ージメチ ルホルムアマイド混合液またはブタノール中へ湿式紡禾を行った。同時に比較のために純 PAN，純 PANと グラフトポリマーとの混合物, PAN-PVAc 混合物, AN-VAc 均一共重合も紡系した。

純 PAN は乳化重合によってつくったものであり,これとPVAc との混合物溶液は長時間放置すると脱混 合するのでそれ以前に紡系した。AN-VAcの均一共重合物はすでに報告したように゙1 AN を追加添加しな がら乳化重合したもので、、ずれもアセトンに可溶であった。グラフト共重合物は乳化重合によってつくり， PVAc を幹としPANを枝とした重合物と考えられる。

紡釆条件を第 4 表に示した。

第 4 表 紡 采

\begin{tabular}{|c|c|c|c|c|}
\hline 実験番号 & ポリマー & $\begin{array}{c}\mathrm{AN} \text { 含量 } \\
(\mathrm{wt} \%)\end{array}$ & 紡浴 & 後延 伸 \\
\hline 21 & 純 PAN & 97.77 & ブタノール & $\begin{array}{l}140 \sim 150^{\circ} \mathrm{C} \\
\text { グリセリン中 }\end{array}$ \\
\hline $16-1$ & $\mathrm{PAN}$ グラフト & 70.21 & " & " \\
\hline $16-2$ & ク゚ラフト & 83.58 & $"$ & " \\
\hline B 1 & PAN-PVAc 混合物 & 71.72 & " & " \\
\hline B 2 & PAN-PVAc 混合物 & 82.29 & " & " \\
\hline $20 \mathrm{f} 1$ & 純 PAN & 98.25 & 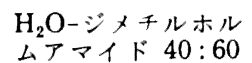 & 沸滕水中 \\
\hline $20 \mathrm{f} 2$ & 純 PAN & 97.88 & " & $"$ \\
\hline $7 \mathrm{f} 3$ & ク゚ラフト & 48.30 & " & " \\
\hline $7 \mathrm{f} 4$ & グラフト & 27.31 & " & " \\
\hline $\mathrm{H} 1$ & 均一共重合物 & 34.82 & $\mathrm{H}_{2} \mathrm{O}$ & 温 水 中 \\
\hline $\mathrm{H} 2$ & 均一共重合物 & 59.60 & " & " \\
\hline $\mathrm{H} 3$ & 均一共重合物 & 68.40 & " & $"$ \\
\hline B 3 & PAN-PVAc 混合物 & 50.0 & $" \prime$ & " \\
\hline
\end{tabular}


表中 $21 \sim \mathrm{B} 2$ の繊維についてグリセリン浴中で延伸し，最高延伸率を求めた結果は第 2 図のようであ り，140〜 $150^{\circ} \mathrm{C}$ の延伸が適当であることがわかった。したがって以下の実験ではこの温度で延伸した。

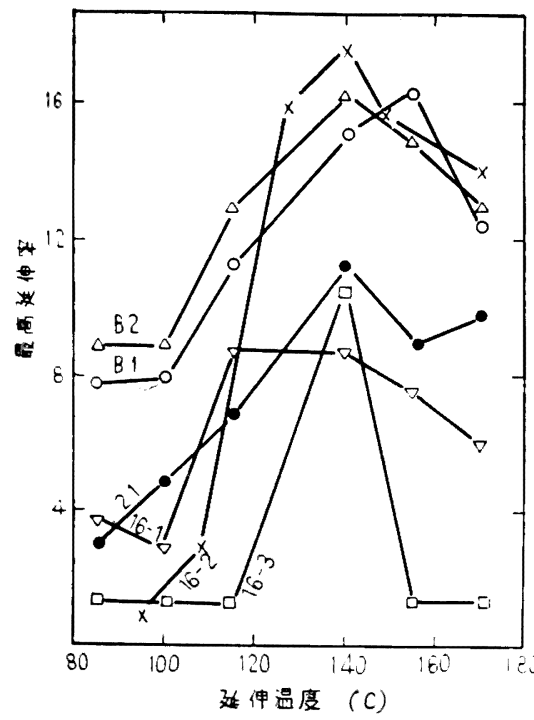

第 2 图延伸温度と最高延伸率との関係

2〜12 倍に延伸した䋊維の強伸度は第 5 表 のようで，延伸による强度增加は各㵶維につ いてほとんど差がない。
第 5 衰 繊維の強伸度

\begin{tabular}{|c|c|c|c|c|}
\hline 試 料 & \begin{tabular}{|l|} 
延伸 \\
倍率
\end{tabular} & $\begin{array}{c}\text { 纎 度 } \\
(\text { den })\end{array}$ & $\begin{array}{l}\text { 強 } \\
\text { (g/den }\end{array}$ & $\begin{array}{c}\text { 伸 度 } \\
(\%)\end{array}$ \\
\hline \multirow[t]{3}{*}{$\operatorname{PAN}(21)$} & 2 & 8.84 & 1.17 & 11.2 \\
\hline & 5 & 3.11 & 3.72 & 13.7 \\
\hline & 8 & 2.21 & 5.27 & 13.0 \\
\hline \multirow[t]{3}{*}{$\mathrm{PAN}-ク ゙ ラ フ ト$ 混合 (16-1) } & 2 & 7.65 & 2.10 & 19.4 \\
\hline & 5 & 2.70 & 3.17 & 15.8 \\
\hline & 8 & 2.46 & 5.50 & 13.9 \\
\hline \multirow[t]{3}{*}{ グラフト (16-2) } & 2 & 18.64 & 1.26 & 8.8 \\
\hline & 5 & 7.44 & 3.83 & 21.7 \\
\hline & 8 & 4.66 & 4.94 & 16.8 \\
\hline \multirow[t]{4}{*}{ PAN-PVAc 混合 (B1) } & 2 & 20.49 & 1.01 & 19.5 \\
\hline & 5 & 10.17 & 2.03 & 16.7 \\
\hline & 8 & 6.81 & 3.13 & 14.1 \\
\hline & 12 & 3.87 & 4.74 & 14.3 \\
\hline \multirow[t]{4}{*}{ PAN-PVAc 混合 (B2) } & 2 & 20.92 & 1.26 & 19.4 \\
\hline & 5 & 11.64 & 2.19 & 18.2 \\
\hline & 8 & 7.82 & 3.37 & 16.9 \\
\hline & 12 & 5.11 & 4.57 & 13.8 \\
\hline
\end{tabular}

この繊維の耐熱性を次のようにして調ぺた。各繊維に $0.01 \mathrm{~g} / \mathrm{den}$ の荷重をかけ，空気浴中で加熱し長さの 変化を測定した。結果は第 6 表のようで，軟化切断温度が純 PAN およびグラフト重合物の方が混合物より 約 $5^{\circ} \mathrm{C}$ 高いということ以外はあまり変りはなかった。

第 6 表 繊維の加熱による収縮（原繊維長 $2.0 \mathrm{~cm}$ )

\begin{tabular}{|c|c|c|c|c|c|c|c|c|c|c|c|c|c|c|c|c|}
\hline 試料 & $25^{\circ} \mathrm{C}$ & 120 & 130 & 150 & 160 & 180 & 195 & 205 & 210 & 220 & 225 & 230 & 235 & 240 & 250 & 255 \\
\hline 21 & 2.0 & 1.9 & 1.8 & 1.8 & 1.8 & 1.7 & 1.7 & 1.7 & 1.5 & 1.4 & 1.4 & 1.4 & 1.4 & 1.3 & 1.2 & 切断 \\
\hline $16-1$ & 2.0 & 1.9 & 1.8 & 1.7 & 1.7 & 1.6 & 1.5 & 1.4 & 1.3 & 1.3 & 1.2 & 1.2 & 1.2 & 1.1 & 1.0 & 切断 \\
\hline $16-2$ & 2.0 & 1.9 & 1.8 & 1.7 & 1.7 & 1.7 & 1.7 & 1.6 & 1.5 & 1.4 & 1.4 & 1.3 & 1.3 & 1.2 & 1.1 & 切断 \\
\hline B 1 & 2.0 & 1.9 & 1.8 & 1.7 & 1.6 & 1.6 & 1.6 & 1.5 & 1.4 & 1.3 & 1.3 & 1.2 & 1.2 & 1.2 & 切断 & \\
\hline B 2 & 2.0 & 1.9 & 1.8 & 1.7 & 1.7 & 1.6 & 1.6 & 1.5 & 1.4 & 1.3 & 1.3 & 1.3 & 1.3 & 1.3 & 切断 & \\
\hline
\end{tabular}

このように AN 含量 70。 以上の㵶維はグラフト重合物も PAN-PVAc 混合物も純 PAN とほとんど差が 認められない(均一共重合物ではすでに報告したように，また第 3 図に示すように AN 含量 70。。程度では $100^{\circ} \mathrm{C}$ 以下で軟化する)。そこで AN 含量を $50 \%$ またはそれ以下にして紡禾した。繊維の耐熱性を第 3 図 に示す。 
図よりわかるように,均一共重合物 ( $\mathrm{H} 1, \mathrm{H} 2$, H3) 耐熱性が悪く、いずれも $100^{\circ} \mathrm{C}$ 以下で 軟化した。PVAc とPAN との等量混合物は, 共重合物よりはるかに軟化点が高い。このこと は，部分ケン化PVAcを紡禾して酢酸基をも つビニロンをつくる際に，均一系部分ケン化物 よりき，完全ケン化物との混合物の方が同一酢 化度でも耐熟水性が大きいという森らの結果“ と同一傾向である。これに対しグラフト共重合

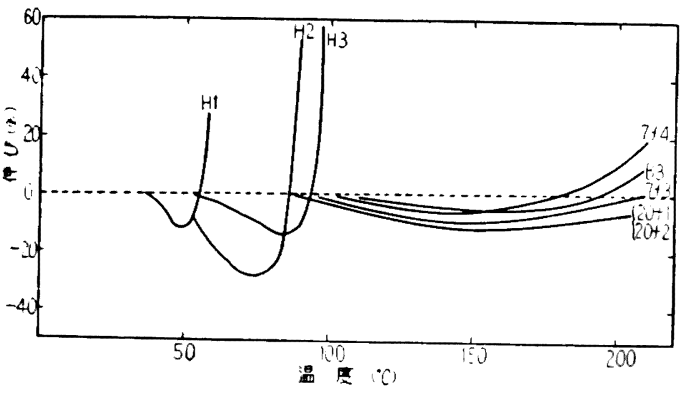

第 3 図繊維の熱耐性 (3 倍延伸繊維, 荷重 $0.01 \mathrm{~g} / \mathrm{d}$, 温度上年 $15^{\circ} \mathrm{C} / \mathrm{min}$ )

物ははるかに耐熱性が大きく，図に示したように純 PAN に近い軟化曲線を示す。ことに $7 \mathrm{f} 4$ は AN 含量 $27.31 \%$ という少量であるにもかかわらず，200 $\mathrm{C}$ に近い軟化点をもっているのは注目すべきことであり，均 一共重合物ならばこの組成では軟化点 $50^{\circ} \mathrm{C}$ 以下である。

このように PVAc を幹とし PAN を枝とするグラフト共重合物繊維が高い軟化点を示すことは Coleman ${ }^{51}$ がテリレン系ブロック共重合瀻維について認めたように, 結晶部分に結晶性ポリマー(ここでは PAN)が集 り, 非結晶性ポリマー(PVAc)は非結晶部分に集るためにPVAcによって結晶が乱されることが少なく、し たがって高い軟化点を示すものと思われる。

\section{女 献}

1) G. Smets and M. Claesen: J. Polym. Sci., 8, 289(1952) ; R.T. Hayes : ibid., 11, 531 (1953) ; 13, 583(1954) ; G.F. Bloomfield : Rubber World, 13, 358(1954)など

2) 岡村, 山下： 䋊学誌, 6, 202(1950)；9, 448, 452(1953)

3) 岡村, 山下: 同上, 6, 505(1950)

4) 森, 田中, 桜井, 岡田：同上, 10, 155 (1954)

5) D. Coleman: J. Polym. Sci., 14, 15(1954)

\section{Polymerization with Presence of Polymers}

\section{Graft-polymerization of Acrylonitrile on to Polyvinyl} Acetate and Its Spinning Experiments

\section{By Takao Yamashita* and Seizo Okamura*}

Acrylonitrile is polymerized in emulsion or solution with presence of polyvinyl acetate and graft polymers are found to form between two polymers. The grafted polymers are spun into fibers from dimethyl formamide solution. The fiber obtained from grafted polymers is more heat-resistant than that of copolymer or mixture. These results are coincided with that previously reported by Mori and Sakurada (on polyvinylalcohol fibers) and also by Coleman (on polyethylene terephthalate fibers).

* Department of Textile-Chemistry, Faculty of Engineering, Kyoto University (Kyoto) 